\title{
Leitthema
}

Gefässchirurgie 2016 · [Suppl 1]: 21:S4-S13

DOI 10.1007/s00772-015-0060-3

Published online: 28 August 2015

(c) The Author(s) 2015. This article is published with open access at Springerlink.com
W. Schäberle ${ }^{1} \cdot$ L. Leyerer ${ }^{1} \cdot$ W. Schierling ${ }^{2} \cdot K_{\text {. Pfister }}^{2}$

${ }^{1}$ Department of Visceral, Vascular, Thorax and Pediatric Surgery, "Klinik am Eichert", Göppingen, Germany

${ }^{2}$ Vascular and Endovascular Surgery, Regensburg University Hospital, Regensburg, Germany

\section{Ultrasound diagnostics} of renal artery stenosis

\section{Stenosis criteria, CEUS and recurrent in-stent stenosis}

\section{Additional online material}

This article includes two additional video sequences on visualizing renal artery stenosis. This supplemental material can be found under: dx.doi.org/10.1007/s00772-0150060-3

\section{Introduction}

Renal artery stenosis (RAS) is found to be the cause of arterial hypertension in $1-5 \%$ of patients [31] and is largely responsible for renal failure requiring dialysis in $5-15 \%$ of patients $[10,13]$. In addition to treatment for hypertension for which, however, there is no significant benefit compared with drug therapy, stent-assisted percutaneous transluminal angioplasty (PTA) is relevant in terms of organ and function preservation in high-grade RAS $[18,36]$.

Intra-arterial renal artery angiography is established as the gold standard for the diagnosis of RAS. A number of studies have evaluated the value of color-coded duplex ultrasonography (CCDS) for screening purposes $[25,50]$. Magnetic resonance angiography (MRA) and computed tomography angiography (CTA) have also become established alongside CCDS. The latter is non-invasive, comparatively cost-effective, widely deployable and permits stenosis grading using hemodynamic measurement parameters; however, study results on stenosis grading are to some extent conflicting.

\section{Measurement methods}

A total of four different methodological approaches to diagnosing RAS using CCDS have been evaluated over the last 25 years, 2 of which measure the degree of stenosis according to direct and 2 according to indirect criteria.

\section{Direct criteria:}

1. Peak systolic velocity (PSV) determines the degree of stenosis according to the continuity equation (PSV is inversely proportional to the crosssectional area affected by stenosis and luminal reduction).

2. The ratio between PSV in the stenosed renal artery and PSV in the aorta (RAR renal aortic ratio) compares the increased intrastenotic flow velocity in the renal arteries with an individual reference value in the aorta. This approach attempts to reduce systemic influencing factors on PSV, such as current blood pressure; however, other factors having a hemodynamic effect on the aorta are difficult to evaluate.

Indirect criteria:

1. Poststenotic Doppler frequency spectra obtained from the renal hilum are evaluated. A reduction in the resistance index $(\mathrm{RI})>0.05$ is an indication of ipsilateral RAS.

2. Delayed acceleration time (AT) distal to high-grade RAS, i.e. delay in systolic rise from end diastole up to PSV on spectral analysis.
As obtaining PSV in the proximal renal arteries can be challenging, some researchers prefer to do this at the renal hilum (indirect criteria). As is known from other vascular territories, indirect criteria only offer reliable accuracy in the case of high-grade stenosis. Although they demonstrate sufficient specificity in $50-70 \%$ of cases depending on the method, sensitivity is poor at approximately $\leq 70 \%$. There is no consensus on the best method to detect RAS using CCDS as each method has its advantages and disadvantages; however, the significant variation in cutoff values above which both direct and indirect criteria assume a $>50 \%$ or $60 \%$ RAS is remarkable. Thus, peak flow velocities of $100-220 \mathrm{~cm} / \mathrm{s}$ are given as the cutoff for $50 \%$ stenosis using the most commonly used parameter, PSV. This achieves at times comparable, at times differing accuracies, a phenomenon that cannot be explained by study design alone.

\section{Examination procedure}

When diagnosing stenosis using direct criteria (e.g. PSV and RAR), the examination takes place with the subject in a supine position. By dosing pressure with a transducer $(2-5 \mathrm{MHz})$ it is possible to suppress artifacts from bowel gas and reduce the required penetration depth. The aorta is sought in cross-section from an epigastric approach and followed from the cranial to the peripheral aspect, where

The German version of this article was published in Gefässchirurgie (2015) 20:102 -111 

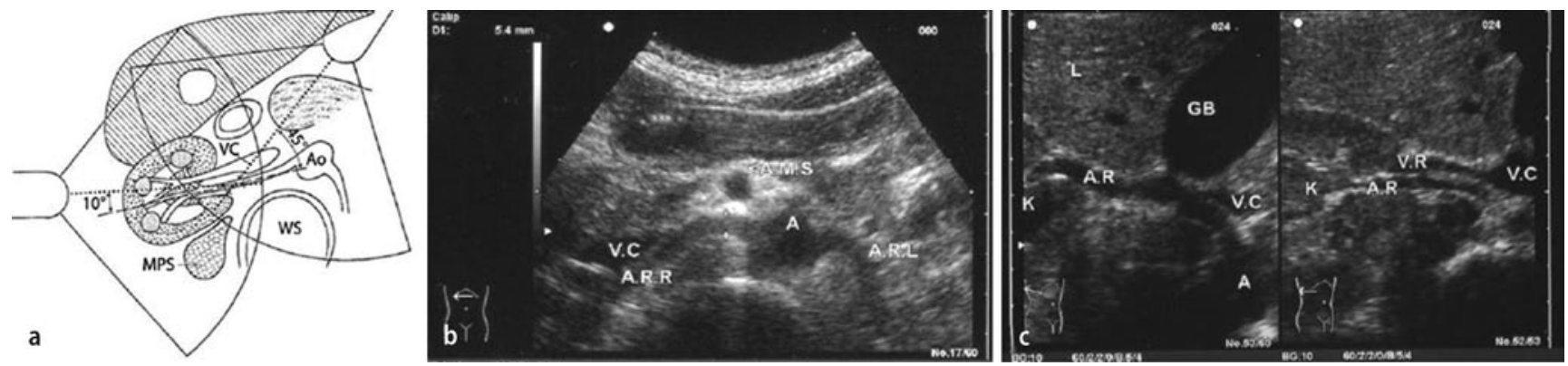

Fig. $1 \Delta$ a Sketch of ultrasound visualization of the renal arteries, epigastric and flanking views [38] (Ao aorta, GB gall bladder, $k$ kidney, MPS ileopsoas muscle, WS spine). b Sonoanatomy with visualization of both renal artery branches (ARR and $A R L)$ originating from the aorta (A). Retrocaval (VC) course of the right renal artery (ARR) [38]. $c$ Visualization of the entire course of the right renal artery $(A R)$ from the renal hilum $(K)$, along a retrocaval course $(V C)$ to the aorta $(A)$ in the left image; right image, the course of the right renal vein $(V R)$ ventral to the artery $(A R)[38]$

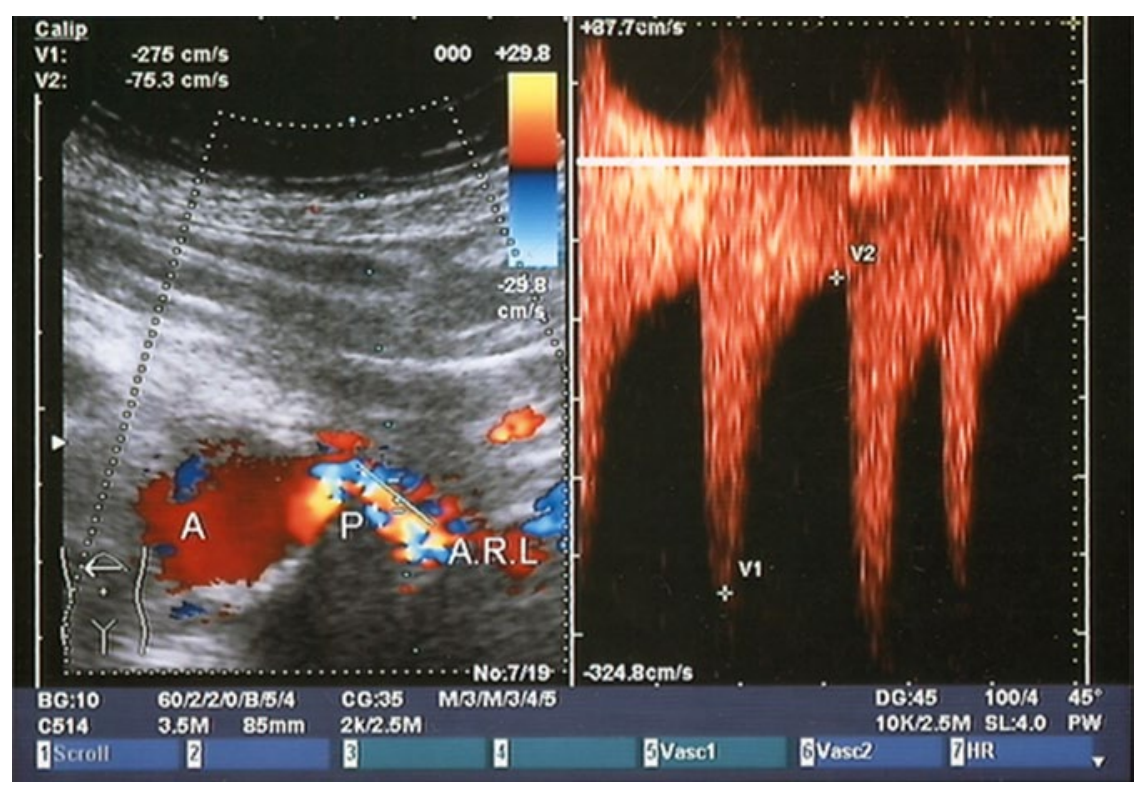

Fig. $2 \Delta$ Left-sided renal artery stenosis (> 70\%) adjacent to the ostium (predilection site for atherosclerotic stenosis) with a PSV of $278 \mathrm{~cm} / \mathrm{s}$ [38]

the renal arteries are located $1-3 \mathrm{~cm}$ distal to the mesenteric artery branch, which can be well localized in cross-section. Two structures that aid renal artery localization are the left renal vein, which courses between the aorta and the superior mesenteric artery to the vena cava. The right renal artery generally courses initially to the right in a ventrolateral direction (approximately 10-11 o'clock position) from the aorta, turns in an arc in a dorsal direction and then continues to run dorsal to the vena cava up to the right renal hilum (- Fig. 1a, b). The left renal artery generally follows a lateral to dorsolateral course (approximately 3-5 o'clock position) from the aorta and then runs in its length of only $4-5 \mathrm{~cm}$ to the renal hilum.
Atherosclerotic stenosis is generally located at the origin of the renal artery. This can be the focus of the examination. Stenosis caused by fibromuscular dysplasia can be found in the middle third. To diagnose stenosis according to indirect criteria (e.g. AT and side to side differences in RI), the renal arteries are scanned on both sides in a flanking section and the renal arteries are visualized in the hilum. If patients are not overly adipose, the renal artery can also be probed in this way (transhepatic section) up to where it arises from the aorta in a right-sided paramedian section (banana peel view) (• Fig. 1c). In order to obtain reliable values despite the relatively error prone measurement method when indirect criteria are used, the mean of multiple measurements (between three and five in total) needs to be taken.

\section{Significance of color-coded duplex sonography in the detection of renal artery stenosis}

\section{Direct criteria}

The significance of CCDS needs to be assessed in a differentiated manner relative to the criteria already described. Compared with the gold standard angiography, PSV demonstrates sensitivities of 71$98 \%$ and specificities of $62-98 \%$, whereby some studies consider $>50 \%$ and others $>60 \%$ as hemodynamically relevant stenosis. The PSV cut-off ranges from 100 to $220 \mathrm{~cm} / \mathrm{s}$ (- Fig. 2). It should be noted here that older studies $[2,11,16,38]$ tended to set lower peak velocities (below $150 \mathrm{~cm} / \mathrm{s})$. These studies were not carried out using CCDS but using a combination of B-mode and Doppler sonography. The lack of color-coded vascular course (flow jet) has shown, also in our own experience, the risk of angle misalignment and hence measurement errors in the PSV approach (• Fig. 3).

Studies conducted using CCDS (mostly after 1993) generally set the cut-off at $180-200 \mathrm{~cm} / \mathrm{s}[8,19,24,27,40,42]$. As peak velocities are determined using receiver operating characteristics (ROC) curves, they also always represent an evaluation performed by the author to assess sensitivity or specificity, positive predictive value (PPV) or negative predictive value (NPV). Thus, a recent pa- 
Gefässchirurgie 2016 • [Suppl 1]: 21:S4-S13 DOI 10.1007/s00772-015-0060-3

(c) The Author(s) 2015

\section{W. Schäberle - L. Leyerer · W. Schierling · K. Pfister \\ Ultrasound diagnostics of renal artery stenosis. Stenosis criteria, CEUS and recurrent in-stent stenosis}

\section{Abstract}

Background and purpose. As a non-invasive, side effect-free and cost-effective method, ultrasonography represents the method of choice for the diagnosis of renal artery stenosis. Four different criteria in total, including two direct criteria in peak systolic velocity (PSV) and renal aortic ratio (RAR) and two indirect criteria in resistance index (RI) and acceleration time (AT) for the measurement of relevant renal artery stenosis are described, each demonstrating highly variable accuracy in studies. Furthermore, there is controversy over the degree beyond which stenosis becomes therapeutically relevant and which ultrasound PSV is diagnostically relevant in terms of stenosis grading.

Material and methods. This article gives a critical review based on a selective literature search on measurement methodology and the validity of ultrasound in renal artery stenosis. A critical evaluation of methods and a presentation of measurement principles to establish the most precise measurement method possible compared with the gold standard angiography, as well as an evaluation of the importance of computed tomography angiography (CTA) and magnetic resonance angiography (MRA).

Results and conclusions. The PSV provides high sensitivity and specificity as a direct measurement method in stenosis detection and grading. Most studies found sensitivities and specificities of $85-90 \%$ for $>50 \%$ stenosis at a PSV $>180-200 \mathrm{~cm} / \mathrm{s}$ in ROC curve analysis. Other methods, such as the ratio of the PSV in the aorta to the PSV in the renal artery (RAR) or indirect criteria, such as side to side differences in $\mathrm{RI}(\mathrm{dRI})$ or AT can be additionally used to improve accuracy. Contrastenhanced ultrasound improves accuracy by means of echo contrast enhancement. Although in the past only high-grade stenosis was considered relevant for treatment, a drop in pressure of $>20 \mathrm{mmHg}$ in $>50 \%$ stenosis (PSV $180 \mathrm{~cm} / \mathrm{s}$ ) is classified as relevant for increased renin secretion. Stenosis in fibromuscular dysplasia can be reliably graded according to the continuity equation. Although the available studies on the grading of in-stent restenosis are the subject of controversy, there is a tendency to assume higher cut-off values for PSV and RAR. Whilst MRA and CTA demonstrate an accuracy of $>90 \%$, this is at the cost of possible side effects for patients, particularly in the case of pre-existing renal parenchymal damage.

\section{Keywords}

Color duplex ultrasonography .

Renal artery stenosis · Stenosis criteria .

Recurrent in stent stenosis .

Contrast enhanced ultrasonography

\section{Ultraschalldiagnostik bei Nierenarterienstenosen. Stenosekriterien, CEUS, In-Stent-Rezidivstenose}

\section{Zusammenfassung}

Hintergrund und Fragestellung. Als nichtinvasives, nebenwirkungsfreies und kostengünstiges Verfahren ist die Sonographie für die Diagnostik der Nierenarterienstenose die Methode der Wahl. Insgesamt vier verschiedene Methoden, zwei direkte („peak systolic velocity", PSV „, renal aortic ratio", RAR) und zwei indirekte Kriterien („,resistance index" $\mathrm{Rl}$, Akzelerationszeit) zur Messung relevanter Nierenarterienstenosen werden beschrieben, jeweils mit sehr unterschiedlichen Treffsicherheiten in verschiedenen Studien. Weiterhin wird kontrovers diskutiert, ab welchem Grad die Stenose therapierelevant ist, und welche sonographische Grenzgeschwindigkeit (PSV) in der Graduierung diagnostische Relevant besitzt. Materialien und Methode. Dieser kritische Review-Beitrag basiert auf einer selektiven Literaturrecherche zu Messmethodik und Validität der Sonographie bei Nierenarterienstenose. Es folgen eine kritische Methoden- evaluation und Darstellung von Messprinzipien zur möglichst exakten Messung verglichen mit dem Goldstandard Angiographie sowie eine Bewertung des Stellenwerts der computertomographischen Angiographie (CTA) und Magnetresonanzangiographie (MRA).

Ergebnisse und Schlussfolgerungen. Die PSV bietet als direkte Messmethode in der Stenosendetektion und Graduierung die höchste Sensitivität und Spezifität. Die meisten Studien ermitteln in ROC-Kurven bei einer PSV $>180-200 \mathrm{~cm} / \mathrm{s}$ Sensitivitäten und Spezifitäten von $85-90 \%$ für $>50 \%$ igen Stenosen. Andere Methoden wie der Quotient aus PSV in Aorta und Nierenarterie (RAR) oder indirekte Kriterien wie der Widerstandsindex im Seitenvergleich (dRI) oder die Akzelerationszeit können ergänzend zu Verbesserung der Treffsicherheit herangezogen werden. Die Kontrastmittelsonographie (CEUS) verbessert durch die Echo- kontrastverstärkung die Treffsicherheit. Früher wurden erst höhergradige Stenosen als therapierelevant angesehen, andererseits wird inzwischen schon der Druckabfall von $>20 \mathrm{mmHg}$ bei $>50 \%$ igen Stenosen (PSV $180 \mathrm{~cm} / \mathrm{s}$ ) als relevant für einen Reninanstieg bewertet. Stenosen bei fibromuskulären Dysplasien können sonographisch nach dem Kontinuitätsgesetz zuverlässig graduiert werden. Die Studienlage für die Graduierung von In-Stent-Rezidivstenosen ist kontrovers, tendenziell höhere Cut-off-Werte für PSV und RAR sind jedoch anzunehmen. MRA und CTA zeigen zwar Treffsicherheiten von $>90 \%$, jedoch mit möglichen Nebenwirkungen für Patienten, insbesondere bei vorbestehendem Nierenparenchymschaden.

\section{Schlüsselwörter}

Farbduplexsonographie ·

Nierenarterienstenose - Stenosekriterien .

In-Stent-Rezidivstenose · CEUS per [1] reported a sensitivity, specificity, PPV, NPV and overall accuracy (OA) of $89 \%, 54 \%, 56 \%, 88 \%$ and $68 \%$, respectively, for a PSV of $200 \mathrm{~cm} / \mathrm{s}$. A PSV of $285 \mathrm{~cm} / \mathrm{s}$ is set as the ideal cutoff for $60 \%$ stenosis. Staub [42] described a PSV of $180 \mathrm{~cm} / \mathrm{s}$ for $50 \%$ stenosis with a sensitivity, specificity, PPV, NPV and OA of $96 \%$, $69 \%, 81 \%, 93 \%$ and $85 \%$, respectively. A PSV of $200 \mathrm{~cm} / \mathrm{s}$ yielded $92 \%, 81 \%, 87 \%$,
$88 \%$ and $87 \%$, respectively, while a PSV of $250 \mathrm{~cm} / \mathrm{s} 78 \%, 92 \%, 93 \%, 75 \%$ and $84 \%$, respectively. This results in an ideal cut-off of $200 \mathrm{~cm} / \mathrm{s}$. Selecting higher PSV as cut-off values inevitably resulted 


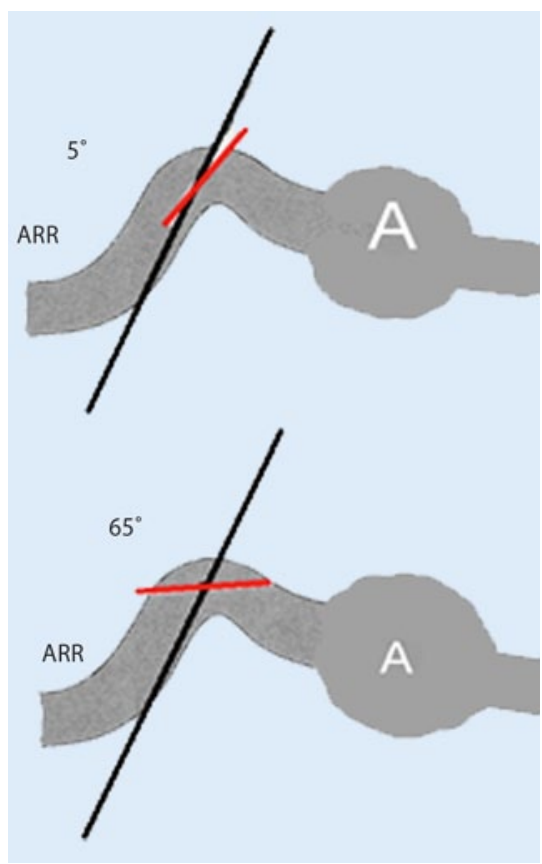

Fig. $3 \Delta$ Difficulty associated with angle adjustment parallel to the flow vectors (vascular wall) in the case of a tortuous course of the renal artery at the origin of the artery (predilection site for atherosclerotic stenosis). At a Doppler angle of $65^{\circ}$, as little as $\pm 5^{\circ}$ angle alignment errors can cause measurement deviations of over $30 \%$ [38]

in lower sensitivity and greater specificity in ROC curves compared with angiography and the converse in the case of a lower PSV. Other causes for differing PSV as peak velocities include the examination method, angle measurement errors (in particular due to the tortuous course of the proximal right renal artery) and the collective investigated (e.g. greater vessel wall rigidity and chronic renal parenchymal damage). Virtually none of the studies addressed systemic factors that influence PSV, such as current blood pressure and vessel wall rigidity. The PSV cut-off values are also strongly influenced by the little discussed problem of adequate stenosis grading in the reference method, angiography. The renal artery is difficult to visualize in the two planes necessary for appropriate grading (only oblique planes possible). Renal artery branch stenosis in particular can be challenging to visualize. Ultrasound PSV grading is generally compared with angiography solely in an anteroposterior plane. Although angiographic diagnosis offers good accura$\mathrm{cy}$, there is poor concordance in stenosis grading between radiologists [49]. For this reason, an own study [38] used X-ray densitometry as an additional reference method and achieved a sensitivity of $86 \%$ and a specificity of $83 \%$ at a PSV cut-off of $140 \mathrm{~cm} / \mathrm{s}$. In addition, a good correlation $(\mathrm{R}=0.84)$ between PSV and X-ray densitometry in stenosis grading of stenosed renal arteries before and after PTA was seen.

Particularly in the case of eccentric stenosis, significant discrepancies are observed between duplex ultrasonography and angiography, the latter showing a far lower hemodynamic effectiveness at the same angiographic diameter reduction compared with concentric stenosis (50\% diameter reduction in concentric stenosis $=75 \%$ area reduction and $50 \%$ diameter reduction in eccentric stenosis $=50 \%$ area reduction). On duplex ultrasonography, the hemodynamic effectiveness of a stenosis is measured as an expression of area reduction. Thus, the PSV in concentric stenosis can be up to twice as high at the same diameter reduction (angiographic data) compared with eccentric stenosis [37].

An RAR of $>3.5$ indicates an over $60 \%$ RAS with a sensitivity of $84-91 \%$ and a specificity of $95-97 \%[16,17,22,47]$. Recent studies were unable to confirm this accuracy, working instead with sensitivities of $73-84 \%$, specificities of $72-81 \%$ and accuracies of $76-78 \%[1,42]$. End-diastolic peak velocity is sometimes also given as a stenosis criterion; however, as a parameter it depends heavily on heart rate and peripheral resistance and the findings, particularly in patients with early renal parenchymal damage cannot be used with sufficient accuracy as increased peripheral resistance causes reduced end-diastolic volume (EDV) early on.

There are currently no studies to validate CCDS specifically in stenosis caused by fibromuscular dysplasia. The main problem lies in the difficulty associated with visualizing the middle third on the left side as a result of gas artifacts from the colon. Comparing spectra and RI at the renal artery branch and at the hilum can be helpful here (see • Fig. 5b). If visualization of the middle third is possible, stenosis grading can be reliably performed via the ratios (PSV ratio) between intrastenotic PSV and PSV in the first third (prestenotic) using the continuity equation (- Fig. 4 and video clip 1). A PSV ratio of $>2$ indicates a stenosis of $>50 \%$ and $>4$ of $>75 \%$ (for concentric stenosis), offering greater grading reliability, as known from peripheral artery stenosis, compared with absolute PSV values.

\section{Indirect criteria}

Spectral analysis of vessels in other arterial territories reveals that indirect criteria only show measurement relevant lesions in the presence of high-grade stenosis. Thus, it is not surprising that a dRI of $>0.05$ (- Figs. 5 and 6 ) as the cut-off for $50 \%$ stenosis has a sensitivity of $42 \%$ and a specificity of $91 \%$ (PPV $69 \%$ and NPV $77 \%$ ). This poor sensitivity, even for $>70 \%$ stenosis, has also been confirmed by Zeller [53] with a sensitivity of $77 \%$ but a specificity of $99 \%$, as well as by Ripollés [33] with a sensitivity of only $50 \%$ and a specificity of $90 \%$ (PPV $69 \%$ and NPV $92 \%)$. Furthermore, Ripollés [33] made the interesting finding that a dRI $>0.05$ could be used only in patients aged $<50$ years with a sensitivity of $90 \%$ and a specificity of $99 \%$. Poststenotic Doppler frequency spectra depend heavily on vessel rigidity and parenchyma function. The typical poststenotic changes (significantly reduced PSV in relation to EDV and prolonged AT) are not as marked in older patients with arteriosclerosis and renal parenchymal damage. On the other hand, a different resistance index (dRI) due to different degrees of renal parenchymal damage on the two sides results in measurement errors. The AT also confirms this with poor sensitivities (around 50\%) and good specificities (around 95\%) [8, 27] in $<80 \%$ RAS.

\section{Treatment-oriented stenosis grading}

Of the different stenosis criteria used a PSV $>180-200 \mathrm{~cm} / \mathrm{s}$ shows the best accuracy for the diagnosis and grading of RAS. To improve the inadequate sensitivities and specificities still seen in some studies, a number of authors recommend combining measurement results from a variety of (direct and indirect) stenosis criteria. In the study conducted by Staub et al. com- 


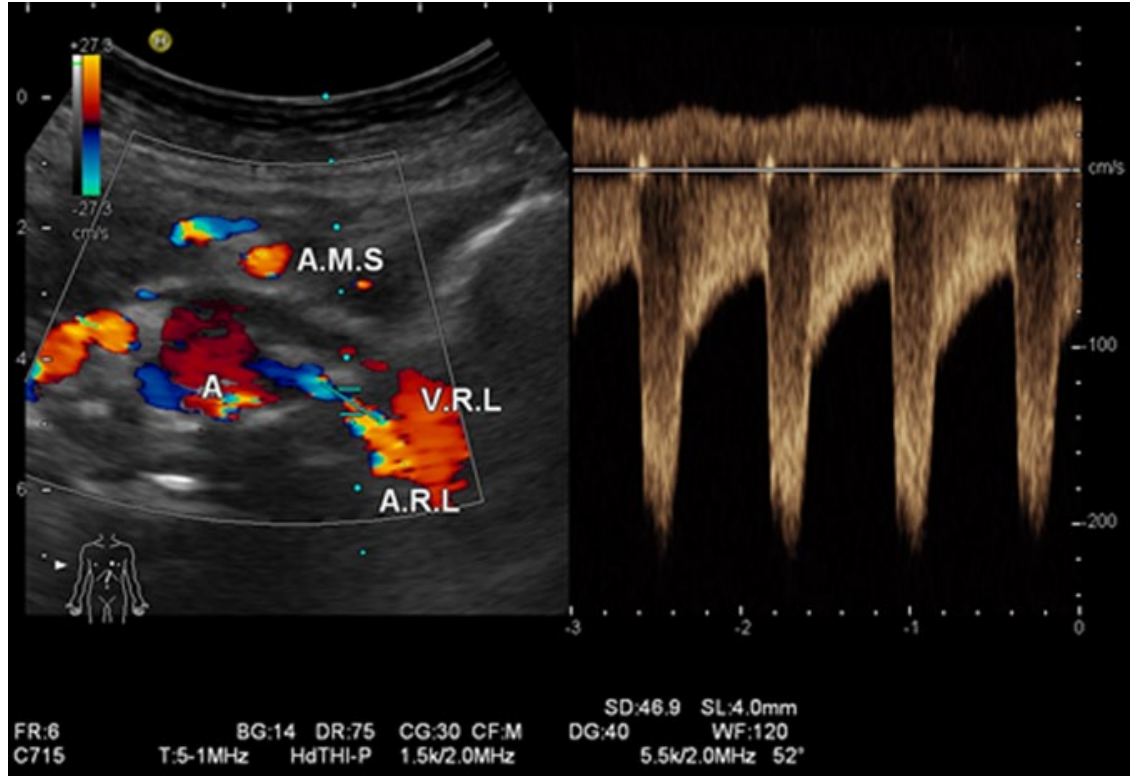

Fig. $4 \Delta$ Fibromuscular dysplasia with $50-60 \%$ stenosis in the middle third (predilection site). PSV ratio $=2.7$ (see also video clip), PSV at the origin of the renal artery $80 \mathrm{~cm} / \mathrm{s}$ and intrastenotic PSV $220 \mathrm{~cm} / \mathrm{s}$ (stenosis grading according to the continuity equation)

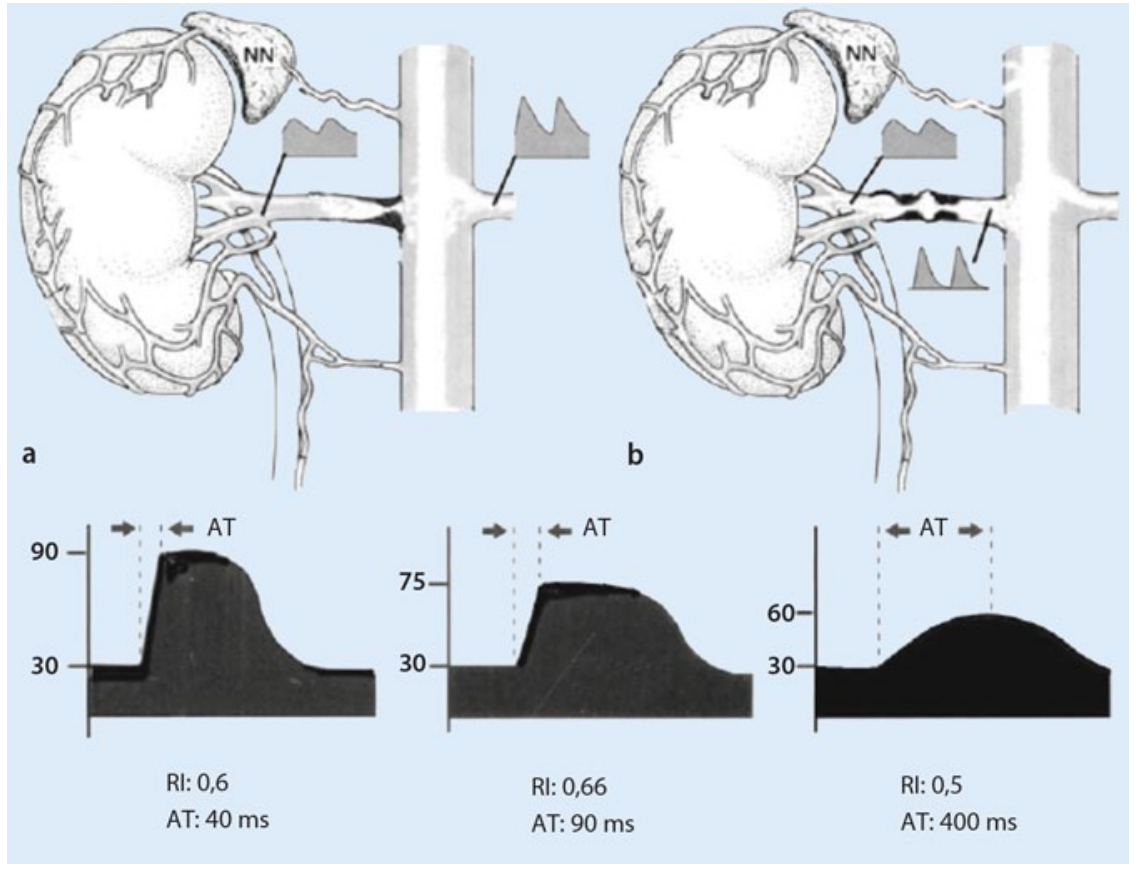

Fig. $5 \Delta$ Poststenotic change in the Doppler frequency spectrum. a Comparison between poststenotic changes right and left. $\mathbf{b}$ Comparison of the Doppler frequency spectrum and RI before and after stenosis caused by fibromuscular dysplasia in the middle third (e.g. in the case of poor visualization of the middle third). c The increasing drop in the Pourcelot resistive index ( $\mathrm{RI}=$ systolic PSV—end-diastolic PSV/systolic PSV) and the increase in acceleration time (AT) with increasing stenosis grade (right normal, middle moderate to high-grade stenosis, right $>90 \%$ stenosis) [38]

bining PSV and RAR yielded sensitivities and specificities of approximately $90 \%$ $[8,24,42]$ using a PSV of $>180 \mathrm{~cm} / \mathrm{s}$ or $200 \mathrm{~cm} / \mathrm{s}$ and an RAR of 3.5. Abu Rahma [1] described the combination of a PSV of
$>285 \mathrm{~cm} / \mathrm{s}$ and an RAR of $>3.5$ as a viable criterion in renal artery diagnostics with a sensitivity of only $60 \%$ but a specificity of $94 \%$, whereby this comparison was made with an angiographic stenosis of over $60 \%$. According to the ROC curve in the same study, a lower cut-off and the combination of a PSV of $>285 \mathrm{~cm} / \mathrm{s}$ and an RAR of $>3.5$ inevitably resulted in a significantly better sensitivity of $73 \%$ but a worse specificity of $81 \%$ (• Table 1$)$; however, the use of several stenosis criteria in the clinical routine is overly complex and time-consuming. For this reason, stenosis detection should be performed primarily by determining PSV and should only be complemented by RAR and dRI in doubtful situations or borderline findings.

The use of CCDS with PSV, as well as the other criteria, shows greater accuracy for the detection of high-grade stenosis. It has hitherto been assumed that only stenosis $>70 \%$ causes a relevant poststenotic pressure drop and increased renin release as a counterregulatory action via the renin-angiotensin system. Thus, only high-grade RAS are considered as requiring treatment $[15,26,28,48]$. It is important to reliably identify these RAS for a treatment-oriented diagnosis. The discussion on the PSV cut-off at $50 \%$ stenosis is more academic in nature than anything else; however, even at $>50 \%$ RSA on angiography (Grosse et al. 2001) [42] measurements of the intra-arterial systolic pressure gradient show a mean pressure gradient of $>22 \mathrm{~mm} \mathrm{Hg}$. In Staub's study [42] a PSV of $>200 \mathrm{~cm} / \mathrm{s}$ (correlating with $50 \%$ stenosis on angiography) showed a mean systolic pressure gradient of $23 \mathrm{mmHg}$ and, hence, hemodynamically relevant stenosis accompanied by a regulatory counteraction [9]; however, it should be pointed out that poststenotic pressure was measured with the catheter lying across the stenosis (additional luminal narrowing).

The method for determining the pressure drop, as validated using the PSV in iliac stenosis [45] across the stenosis using the simplified Bernoulli equation (drop in pressure $\mathrm{dP}=4 \times$ intrastenotic $\mathrm{PSV}^{2}$ ) is only reliable in high-grade stenosis, as the prestenotic PSV is considered negligible in this context. In the case of renal artery branch stenosis, the prestenotic PSV in the aorta cannot be used. The poststenotic PSV [ $\mathrm{dP}=4 \times$ (intrastenotic PSV $^{2-}$ poststenotic $\mathrm{PSV}^{2}$ )] occasionally used instead [46] of the prestenotic PSV (in the Bernoulli equation) is inaccurate and ne- 


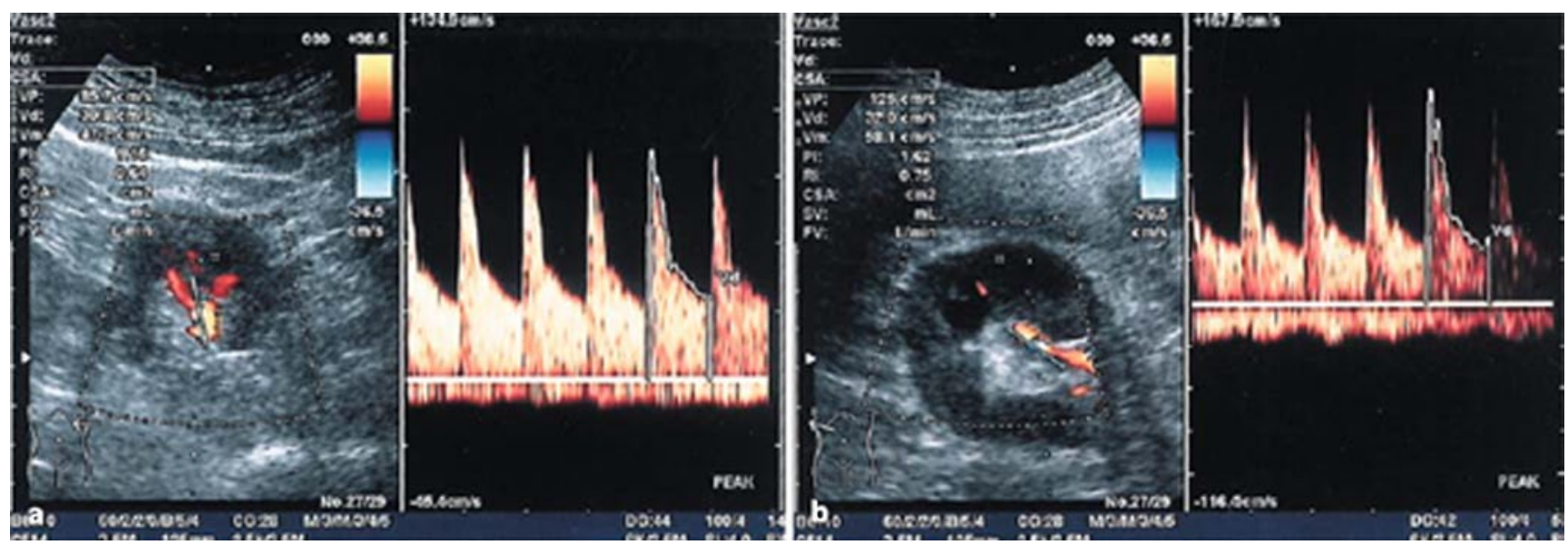

Fig. $6 \Delta$ Comparison of the left-sided $(R I=0.64)$ and right-sided $(R I=0.75)$ resistance index for the detection of renal artery stenosis. Left $\mathrm{Rl}>10 \%$ lower than right indicates left-sided stenosis (see $\bullet$ Fig. 2 )
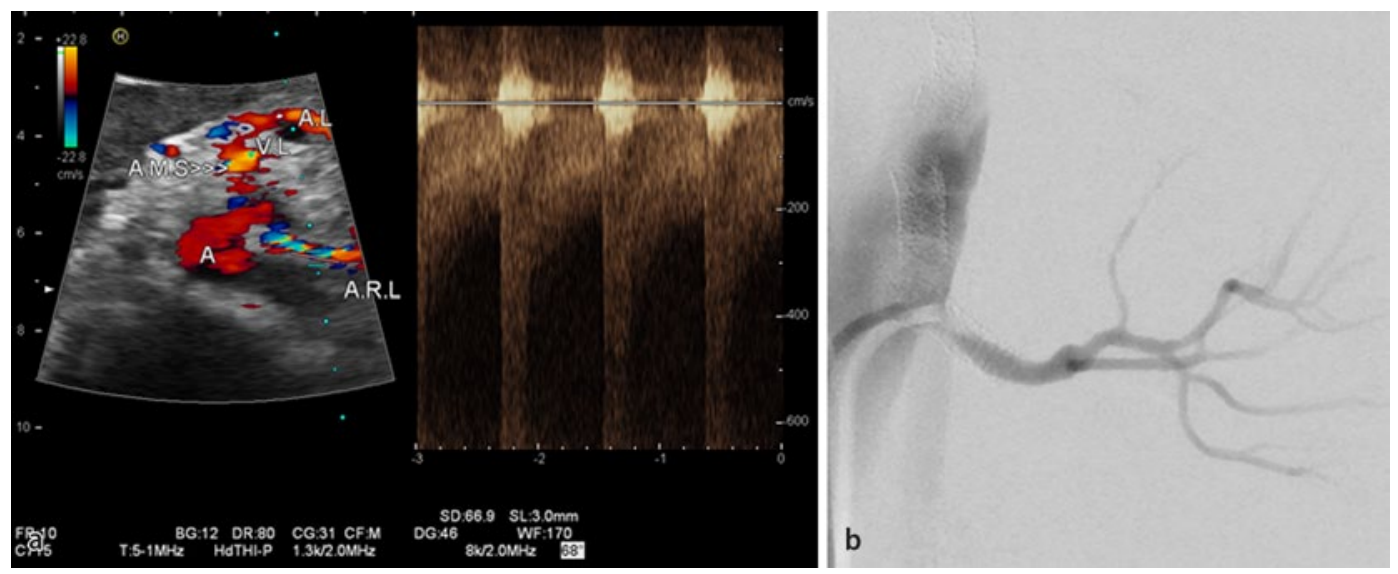

Fig. $7 \Delta$ a High-grade left-sided in-stent restenosis (see also video clip) with a PSV of $>5.5 \mathrm{~m} / \mathrm{s}$ and marked turbulence where the stent protrudes into the aortic lumen causing hyperechogenicity ( $A$ aorta, $A M S$ superior mesenteric artery, $A L$ splenic artery, $A R L$ left renal artery, $V L$ splenic vein). $\mathbf{b}$ Angiography of high-grade in-stent restenosis (probing at the origin of the renal artery stent protruding into the aortic lumen. Additional stent at the origin of the mesenteric artery projected on the aorta)

glects inertial and frictional losses over the stenosis.

\section{Contrast-enhanced ultrasonography}

A study including 120 patients with 38 stenosed renal arteries reported surprisingly good results [6]. Sensitivity, specificity, PPV, NPV and accuracy were reported as being $100 \%, 84 \%, 0 \%, 80 \%$ and $94 \%$, respectively, for CCDS compared with angiography in the same study. Claudon [7] described a $20 \%$ improvement (from $63.9 \%$ to $83.9 \%$ ) in stenosis detection in RAS using contrast-enhanced ultrasonography (CEUS) compared with conventional CCDS. In an already somewhat older study Missouris et al. found an increase in sensitivity from $85 \%$ to $94 \%$ and in specificity from $79 \%$ to $88 \%$ with a $20 \mathrm{~dB}$ increase in Doppler intensity following contrast medium administration.

\section{Ultrasound follow-up after stent placement}

Using PSV and RAR in in-stent restenosis tend to show higher cut-off values at an equivalent degree of stenosis on angiography compared with native RAS [5, 12]; however, study results are conflicting. The explanation given for this in carotid artery restenosis is stent rigidity and a luminal reduction due to the stent. While Chi [5] set the ideal PSV cut-off for albeit $>70 \%$ stenosis in stented renal arteries at $>395 \mathrm{~cm} / \mathrm{s}$ and a RAR of $>5.1$, Fleming [12] demonstrated a sensitivity, specificity, PPV and accuracy of $73 \%, 80 \%, 64 \%$ and $77 \%$ for $>60 \%$ stenosis at a PSV of $>180 \mathrm{~cm} / \mathrm{s}, 68 \%, 80 \%, 63 \%$ and $76 \%$ at $>200 \mathrm{~cm} / \mathrm{s}$ and $59 \%, 95 \%, 87 \%$ and $83 \%$ at $>250 \mathrm{~cm} / \mathrm{s}$.

According also to these ROC curves, the selection of the ideal PSV cut-off should depend on the objective. If as much restenosis as possible is to be detected, a PSV of $180 \mathrm{~cm} / \mathrm{s}$ should be selected due to its high sensitivity (73\%). If the focus lies on high-grade stenosis (where only this stenosis is considered relevant in terms of reintervention) a PSV with the highest PPV and specificity should be selected $(87 \%$ and $95 \%$, respectively for a PSV $>250 \mathrm{~cm} / \mathrm{s}$ ).

Controversially, Nolan [30] found similar stenosis velocity criteria for stented renal arteries compared with native stenosis (PSV $>200 \mathrm{~cm} / \mathrm{s}$ and RAR $>3.5$ ). Singh 


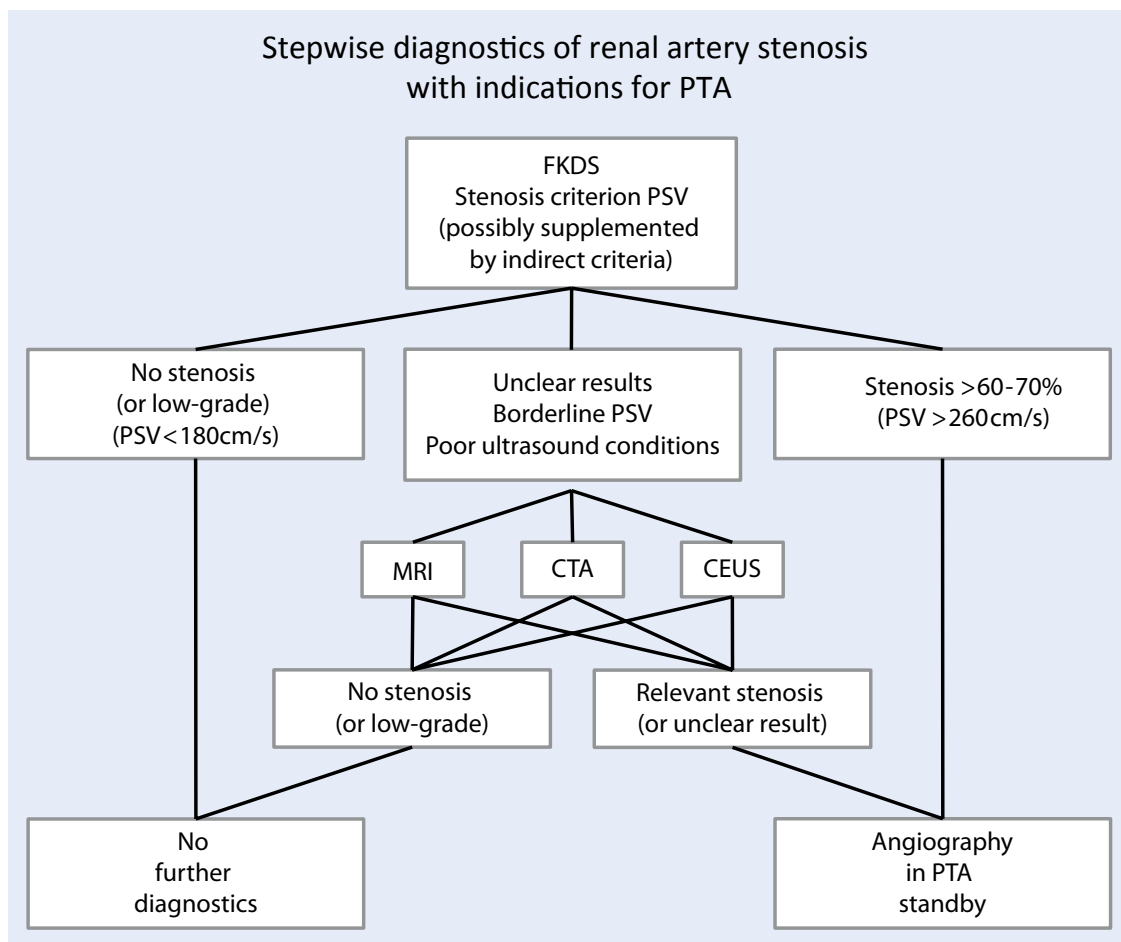

Fig. $8 \Delta$ Stepwise diagnostics of renal artery stenosis (CEUS, contrast-enhanced ultrasonography, CTA computed tomography angiography, FKDS color flow imaging, MRI magnetic resonance imaging, PSV peak systolic velocity, PTA percutaneous transluminal angioplasty)

[34] also obtained the same results (PSV $>225 \mathrm{~cm} / \mathrm{s}$ and RAR $>3.5 \%$ ). Napoli [29] even reduced the values for stented renal arteries (PSV from $180 \mathrm{~cm} / \mathrm{s}$ to $144 \mathrm{~cm} / \mathrm{s}$ and RAR from $3.5 \%$ to $2.53 \%$ ) in order to improve sensitivity and specificity. Our own attempts to explain these results involved asking the question whether instent restenosis in this collective was more eccentric, which exhibits less area reduction and hence less hemodynamic relevance and lower PSV compared with concentric stenosis at equivalent angiographic diameter reduction.

Besides the problems already described for native stenosis in stenosis detection using ultrasound compared with angiography, other weaknesses of poststenting studies lie in the low case numbers in generally retrospective, single center studies. Additional sources of error include a selection bias (angiographic follow-up only in clinically and sonographically proven pathological results), lack of information on the degree to which stenosis could be assessed (ultrasound conditions and angle alignment errors) and the impact of systemic factors on hemodynamics, meaning that some authors $[5$,
12] themselves questioned the possibility that their study results were a generalization (• Fig. 7).

\section{Computed tomography angiography}

The advent of multislice CTA and its ability to gather high-speed, thin-slice volume data sets has made it possible, in contrast to earlier technologies, to adequately assess the renal arteries. Although intra-arterial digital subtraction angiography (DSA) is still considered the gold standard, CTA overcomes the limitation whereby vessels (or luminal narrowing) can be visualized only intraluminally and provides images on wall calcification and lumen-narrowing plaque via three-dimensional data sets. Thus, studies conducted in recent years have shown sensitivities of $90-100 \%$ and specificities of $92-$ $98 \%[4,21,35,52]$. Only the controversially discussed (study design) prospective multicenter Renal Artery Diagnostic Imaging Study in Hypertension (RADISH) has shown sobering results, with a sensitivity of $64 \%$ and specificity of $92 \%$. Problems arise in the assessment of accessory renal arteries (pole arteries). With sensitivities of $100 \%$ and specificities of $99 \%$, CTA yielded very good results in the assessment of in-stent stenosis following stent-assisted PTA in a study on 95 renal artery stents [44]. In addition to radiation exposure and possible contrast medium-induced nephropathy, particularly in patients with pre-existing parenchymal damage, the snapshot in time obtained with CTA and its inability to visualize hemodynamics, represents a further disadvantage.

\section{Magnetic resonance angiography}

With sensitivities and specificities of 88 $100 \%$ [50], contrast-enhanced MRA is well suited as a non-invasive method to diagnose RAS; however, as known from other vascular territories, it overestimates the degree of stenosis by $26-32 \%[14,23$, 43]. It also shows good accuracy in the visualization of accessory renal arteries [3, $14,39,51]$ as well as in the assessment of fibromuscular dysplasia [53]; however, the sensitivity was only $68 \%$ for the grading of relevant stenosis in fibromuscular dysplasia.

In addition to a morphological assessment of the renal arteries, MRA also permits a functional assessment of the kidneys (renal parenchymal flow). Besides the known contraindications (i.e. nephrophathy and pacemakers), MRA is also susceptible to artifacts from neighboring metal or gas-containing organs, which can simulate stenosis. Furthermore, the broad application of gadolinium-enhanced MRA is limited due to the risk of nephrotoxicity and fibrosis, particularly in patients with impaired renal function and reduced glomerular filtration rate.

\section{Conclusion}

Being a non-invasive, cost-effective and radiation-free examination method with good sensitivities and specificities (approximately $90 \%$ ), CCDS is well suited to the diagnosis of RAS. An intrastenotic PSV $>180-200 \mathrm{~cm} / \mathrm{s}$ represents the most accurate stenosis criterion for stenosis $>50 \%$. In the case of inconclusive findings, this criterion can be complemented 
Table 1 Color-coded duplex ultrasonography in the diagnosis of renal artery stenosis (RAS). Angiography-controlled studies on accuracy in hemodynamically relevant RAS. Various criteria are combined (direct and indirect stenosis criteria) to increase accuracy in RAS diagnosis

\begin{tabular}{|c|c|c|c|c|c|}
\hline Author & Number $(N)$ (stenosis degree) & Method/stenosis criterion & Sensitivity & Specificity & Reference method \\
\hline \multirow[t]{3}{*}{ Zeller et al. [53] } & \multirow[t]{3}{*}{$69(>70 \%)$} & RAR $>3.5$ & $100 \%$ & $60 \%$ & Angiography \\
\hline & & $\mathrm{dRI}>0.5$ & $77.5 \%$ & $99 \%$ & Angiography \\
\hline & & $\mathrm{RAR}>3.5$ and $\mathrm{dRI}>0.05$ & $76 \%$ & $97 \%$ & Angiography \\
\hline Krumme et al. [24] & $135(>50 \%)$ & PSV $>200$ and $d R I>0.05$ & $89 \%$ & $92 \%$ & Angiography \\
\hline \multirow[t]{2}{*}{ Motew et al. [27] } & \multirow[t]{2}{*}{$41(>60 \%)$} & $\mathrm{PSV}>180 \mathrm{~cm} / \mathrm{s}$ & $94 \%$ & $88 \%$ & Angiography \\
\hline & & AT $>58 \mathrm{~ms}$ & $58 \%$ & $96 \%$ & Angiography \\
\hline & & \multicolumn{4}{|c|}{ Conclusion: combination of methods recommended } \\
\hline \multirow[t]{6}{*}{ Ripollés et al. [33] } & $60(>75 \%)$ & AT $>80 \mathrm{~ms}$ & $89 \%$ & $99 \%$ & Angiography \\
\hline & Age $<50$ years & AT $>80 \mathrm{~ms}$ & $100 \%$ & $100 \%$ & Angiography \\
\hline & Age $>50$ years & AT $>80 \mathrm{~ms}$ & $75 \%$ & $97 \%$ & Angiography \\
\hline & Age $<50$ years & $\mathrm{dRI}>0.05$ & $90 \%$ & $93 \%$ & Angiography \\
\hline & $\mathrm{Ag}>50$ years & $\mathrm{dRI}>0.05$ & $0 \%$ & $100 \%$ & Angiography \\
\hline & & \multicolumn{4}{|c|}{ Conclusion: $\mathrm{dRI}$ and $\mathrm{AT}$ only useful as stenosis criterion in patients aged $<50$ years } \\
\hline Rademacher et al. [32] & $226(>50 \%)$ & $\begin{array}{l}\text { PSV } \\
>180 \mathrm{~cm} / \mathrm{s} \text { and PSV hilum } \\
<1 / 4 \text { PSV max. (Stenose) } \\
\text { AT } \\
>70 \mathrm{~ms}\end{array}$ & $96 \%$ & $98 \%$ & Angiography \\
\hline Souza de Oliveira et al. [41] & $60(>50 \%)$ & PSV $>150 \mathrm{~cm} / \mathrm{s}$ & $83.3 \%$ & $89.3 \%$ & Angiography \\
\hline \multirow[t]{6}{*}{ Conkbayir et al. [8] } & \multirow[t]{6}{*}{$50(>60 \%)$} & PSV $>180 \mathrm{~cm} / \mathrm{s}$ & $89 \%$ & $88 \%$ & Angiography \\
\hline & & RAR $>3.0$ & $86 \%$ & $97 \%$ & Angiography \\
\hline & & AT $>70 \mathrm{~ms}$ & $48 \%$ & $93 \%$ & Angiography \\
\hline & & PSV $>180 \mathrm{~cm} / \mathrm{s}$ or $\mathrm{RAR}>3.0$ & $92 \%$ & $88 \%$ & Angiography \\
\hline & & $\begin{array}{l}\mathrm{PSV}>180 \mathrm{~cm} / \mathrm{s} \text { or RAR }>3.0 \\
\text { or AT }>70 \mathrm{~ms}\end{array}$ & $87 \%$ & $86 \%$ & Angiography \\
\hline & & \multicolumn{4}{|c|}{ Conclusion: combination of methods recommended } \\
\hline Kawarada et al. [20] & $\begin{array}{l}94 \\
60 \% \\
\end{array}$ & PSV $>219$ & $89 \%$ & $89 \%$ & $\begin{array}{l}\text { Angiography, transstenotic } \\
\text { pressure gradient }\end{array}$ \\
\hline \multirow[t]{7}{*}{ Straub et al. [42] } & $49(>50 \%)$ & PSV $>200$ & $92 \%$ & $81 \%$ & $\begin{array}{l}\text { Angiographic stenosis de- } \\
\text { gree, pressure gradient }\end{array}$ \\
\hline & & RAR $>3.0$ & $83 \%$ & $91 \%$ & Angiography \\
\hline & & $\mathrm{dRI}>0.05$ & $31 \%$ & $97 \%$ & Angiography \\
\hline & \multirow[t]{4}{*}{$49(>70 \%)$} & $\mathrm{PSV}>250 \mathrm{~cm} / \mathrm{s}$ & $89 \%$ & $70 \%$ & \multirow{3}{*}{$\begin{array}{l}\text { Angiography, angiographic } \\
\text { stenosis degree, intra-arte- } \\
\text { rial pressure measurement } \\
\text { over stenosis }\end{array}$} \\
\hline & & RAR $>3.5$ & $84 \%$ & $72 \%$ & \\
\hline & & $\mathrm{dRI}>0.05$ & $42 \%$ & $91 \%$ & \\
\hline & & \multicolumn{4}{|c|}{ PSV recommended possibly in combination with RAR (and dRI) to increase specificity } \\
\hline Solar et al. [40] & $\begin{array}{l}94 \\
60 \%\end{array}$ & PSV $>180$ & $85 \%$ & $84 \%$ & Angiography \\
\hline \multirow[t]{5}{*}{ Abu Rahma et al. [1] } & $\begin{array}{l}313 \\
60 \% \\
\end{array}$ & PSV180 & $91 \%$ & $41 \%$ & Angiography \\
\hline & & PSV $>285$ & $67 \%$ & $90 \%$ & Angiography \\
\hline & & RAR $>3.5$ & $72 \%$ & $81 \%$ & Angiography \\
\hline & & $\begin{array}{l}\text { PSV } \\
180+ \\
\text { RAR } \\
3.5 \\
\end{array}$ & $73 \%$ & $81 \%$ & Angiography \\
\hline & & $\begin{array}{l}\text { PSV } \\
285+ \\
\text { RAR } \\
3.5\end{array}$ & $60 \%$ & $94 \%$ & Angiography \\
\hline Schäberle et al. [40] & $91(>50 \%)$ & $\mathrm{PSV}>140 \mathrm{~cm} / \mathrm{s}$ & $86 \%$ & $83 \%$ & $\begin{array}{l}\text { X-ray densitometry, angi- } \\
\text { ography }\end{array}$ \\
\hline
\end{tabular}


by RAR or indirect criteria. It is possible to improve accuracies using CEUS. The MRA and CTA, with their good accuracy in the case of doubtful or borderline findings, offer an additional investigation method, albeit at the cost of higher patient exposure. Alternatively, when clinical findings are relevant to treatment, DSA can be performed on stand-by to convert to PTA (• Fig. 8).

\section{Corresponding address}

\section{Dr.W. Schäberle}

Department of Visceral, Vascular, Thorax and Pediatric Surgery

"Klinik am Eichert"

Eichertstr. 3, 73035 Göppingen

wilhelm.schaeberle@kae.de

\section{Compliance with ethical guidelines}

Conflict of interest. W. Schäberle, L. Leyerer, W. Schierling and K. Pfister state that there are no conflicts of interest.

This article does not include studies on humans or animals.

Open Access This article is distributed under the terms of the Creative Commons Attribution 4.0 International License (http://creativecommons.org/ licenses/by/4.0/), which permits unrestricted use, distribution, and reproduction in any medium, provided you give appropriate credit to the original author(s) and the source, provide a link to the Creative Commons license, and indicate if changes were made.

\section{References}

1. Abu Rahma AF, Srivastava M, Mousa AY (2012) Critical analysis of renal duplex ultrasound parameters in detecting significant renal artery stenosis. J Vasc Surg 56:1052-1060

2. Avasthi PS, Voyles WF, Greene ER (1984) Noninvasive diagnosis of renal artery stenosis by echoDoppler velocimetry. Kidney Int 25:824-829

3. Bakker J, Beek FJ, Beutler JJ (1998) Renal artery stenosis and accessory renal arteries: accuracy of detection and visualization with gadolinium-enhanced breath-hold MR angiography. Radiology 207:497-504

4. Beregi JP, Louvegny S, Ceugnart L (1997) Helical xray computed tomography of renal arteries. Apropos of 300 patients. J Radiol 78:549-556

5. Chi YW, White CJ, Thornton S, Milani RV (2009) UItrasound velocity criteria for renal in-stent restenosis. J Vasc Surg 50:119-123
6. Ciccone MM, Cortese F, Fiorella A, Scicchitano $P$, Cito F, Quistelli G, Pertosa G, D'Agostino R, Guida P, Favale S (2011) The clinical role of contrast-enhanced ultrasound in the evaluation of renal artery stenosis and diagnostic superiority as compared to traditional echo-color-Doppler flow imaging. Int Angiol 30:135-139

7. Claudon M, Plouin PF, Baxter GM, Rohban T, Devos DM (2002) Renal arteries in patients at risk of renal arterial stenosis: multicenter evaluation of the echo-enhancer SH U 508A at color and spectral Doppler US. Levovist Renal Artery Stenosis Study Group. Radiology 214:739-746

8. Conkbayir I, Yucesoy C, Edguer T (2003) Doppler sonography in renal artery stenosis. An evaluation of intrarenal and extrarenal imaging parameters. Clin Imaging 27:256-260

9. De Bruyne B, Manoharan G, Pijls NH (2006) Assessment of renal stenosis severity by pressure gradient measurements. J Am Coll Cardiol 48:18511855

10. Derkx FH, Schalekamp MA (1994) Renal arterystenosisandhypertension. Lancet 344:237-239

11. Ferretti G, Salomone A, Castagno PL (1988) Renovascular hypertension: a non-invasiv duplex scanning screening. Int Angiol 7:219-223

12. Fleming SH, Ross PD, Timothy EC (2010) Accuracy of duplex sonography scans after renal artery stenting. J Vasc Surg 52:953-958

13. Garovic VD, Textor SC (2005) Renovascular hypertension and ischemic nephropathy. Circulation 112:1362-1374

14. Glifeather M, Yoon HC, Siegelman ES (1999) Renal artery stenosis: evaluation with conventional angiography versus gadolinium-enhanced MR angiography. Radiology 210:367-372

15. Guo Z, Fenster A (1996) Three-dimensional power Doppler imaging: a phantom study to quantify vessel stenosis. Ultrasound Med Biol 22:10591069

16. Hansen KJ, Tribble RW, Reavis SW (1990) Renal duplex sonography: evaluation of clinical utility. J VascSurg 12:227-236

17. Hawkins PG, McKnoulty LM, Gordon RD (1989) Noninvasive renal artery duplex ultrasound and computerized nuclear renography to screen for and follow progress in renal artery stenosis. J Hypertens Suppl 7:184-185

18. Hirsch AT, Haskal ZJ, Hertzer NR (2006) ACC/AHA 2005 partice guidelines for the management of patients with peripheral arterial disease (lower extremity, renal, mesenteric, and abdominal aortic): a collaborative report from the American Association for Vascular Surgery/Society for Vascular Surgery. Society for Cardiovascular Angiography and Interventions, Society for Vascular Medicine and Biology, Society of Interventional Radiology, and the ACC/AHA Task Force on Practice Guidelines (Writing Committee to Develop Guidelines for the Management of Patients With Peripheral Arterial Disease). Circulation 113:e463-e654

19. Karasch T, Strauss AL, Grün B, Worringer M, Neuerburg-Heusler D, Roth FJ, Rieger H (1993) Farbkodierte Duplexsonographie in der Diagnostik von Nierenarterienstenosen. Dtsch Med Wochschr 118:1429-1436

20. Kawarada O, Yokoi Y, Yakemoto K et al (2006) The performance of renal ultrasonography for the detection of hemodynamically significant renal artery stenosis. Catheter Cardiovasc Interv 68:311318

21. Kim TS, Chung JW, Park JH (1998) Renal artery evaluation: comparison of spiral CT angiographyto intra-arterial DSA. J Vasc Interv Radiol 9:553-559
22. Kohler TR, Zierler RE, Martin RL (1986) Noninvasive diagnosis of renal artery stenosis by ultrasonic duplex scanning. J Vasc Surg 4:450-456

23. Krinsky G, Rofsky N, Giangola G (1996) Gadolinium-enhanced three-dimensional MR angiography of acquired arch vessel disease. AJR Am J Roentgenol 167:981-987

24. Krumme B, Blum U, Schwertfeger E (1996) Diagnosis of renovascular disease by intra- and extrarenal Doppler scanning. Kidney Int 50:1288-1292

25. Leiner T, de Haan MW, Nelemans PJ (2005) Contemporary imaging techniques for the diagnosis of renal artery stenosis. Eur Radiol 15:2219-2229

26. May AG, Deweese JA, Rob CG (1963) Hemodynamic effects of arterial stenosis. Surgery 53:513-524

27. Motew SJ, Cherr GS, Craven TE (2000) Renal duplex sonography: main renal artery versus hilaranaylsis. J Vasc Surg 32:462-471

28. Muster BR, Williams DM, Prince MR (1998) In vitro model of arterial stenosis: correlation of MR signal dephasing and trans-stenotic pressure gradients. Magn Reson Imaging 16:301-310

29. Napoli V, Pinto S, Bargellini I, Vignali C, cioni R, Petruzzi P (2002) Duplex ultrasonographic study of the renal arteries before and after renal artery stenting. Eur Radiol 12:796-803

30. Nolan BW, Schermerhorn ML, Powell RJ, Rowell E (2005) Restenosis in gold-coated renal artery stents. J Vasc Surg 42:40-46

31. Olin JW (2002) Atherosclerotic renal artery disease. Cardiol Clin 20:547-562

32. Radermacher J, Chavan A, Schäffer J (2000) Detection of significant renal artery stenosis with color Doppler sonography: combining extrarenal and intrarenal approaches to minimize technical failure. Clin Nephrol 53:333-343

33. Ripolles T, Aliaga R, Morote V (2001) Utility of intrarenal Doppler ultrasound in the diagnosis of renal artery stenosis. Eur J Radiol 40:54-63

34. Rocha-Singh K, Jaff MR, Lynne Kelly E (2008) RENAISSANCE Trial Investigators. renal artery stenting with noninvasive duplex ultrasound followup: 3 -year results from the RENAISSANCE renal stent trial. Catheter Cardiovasc Interv 72:853-862

35. Rountas C, Vlychou M, Vassiou K (2007) Imaging modalities for renal artery stenosis in suspected renovascular hypertension: prospective intraindividual comparison of color Doppler US, CT angiography, GD-enhanced MR angiography and digital subtraction angiography. Ren Fail 29:295-302

36. Safian RD, Textor SC (2001) Renal-artery Stenosis. N Engl J Med 344:431-442

37. Schäberle W (2009) Ultraschall in der Gefäßdiagnostik, 3. Aufl. Springer, Heidelberg, S 338, 402409, 450-455

38. Schäberle W, Strauss A, Neuerburg-Heusler D, Roth FJ (1992) Wertigkeit der Duplexsonographie in der Diagnostik der Nierenarterienstenose und ihre Eignung in der Verlaufskontrolle nach Angioplastie (PTA). Ultraschall Med 13:271-276

39. Shetty AN, Bis KG, Kirsch M (2000) Contrast-enhanced breath-hold three-dimensional magnetic resonance angiography in the evaluation of renal arteries: optimization of technique and pitfalls. J Magn Reson Imaging 12:912-923

40. Solar M, Zizka J, Krajina A, Michl A, Raupach J, Kizo L, Ryska P, Ceral J (2011) Comparison of duplex ultrasonography and magnetic resonance imaging in the detection of significant renal artery stenosis. Acta Medica 54(1):9-12

41. Souza de Oliveira IR, Widmann A, Molnar LJ (2000) Colour Doppler ultrasound: a new indes improves the diagnosis of renal artery stenosis. Ultrasound Med Biol 26:41-47 
42. Staub D, Canevascini R, Huegli RW, Aschwanden $M$, Thalhammer C, Imfeld S, Singer E, Jacob AL, Jaeger KA (2007) Best duplex-sonographic criteria for the assessment of renal artery stenosis - correlation with intra-arterial pressure gradient. Ultraschall Med 28:45-51

43. Steffens JC, Link J, Graessnerr J (1997) Contrast-enhanced, K-space-centered, breath-hold MR angiography of renal arteries and the abdominal aorta. J Magn Reson Imaging 7:617-622

44. Steinweder C, Schutzenberger W, Fellner F (2009) 64-Detector $\mathrm{CT}$ angiography in renal artery stent evaluation: prospective comparison with selective catheter angiography. Radiology 252:299-305

45. Strauss AL, Roth FJ, Rieger H (1993). Noninvasive assessment of pressure gradients across iliac artery stenosis: duplex and catheter correlative study. J Ultrasound Med 12:17-22

46. Stock KF (2009) Ultraschalldiagnostik der Nierengefäße und der Transplantatniere. Radiologe 49:1040-1047

47. Taylor DC, Kettler MD, Monetta GL et al (1988) Duplex ultrasound in the diagnosis of renal artery: a prospective evaluation. J Vasc Surg 7:363-769

48. Textor SC (1994) Renovascular Hypertension. Endocrinol Metabol Clin North Am 23:235-253

49. Van Jaarsveld $B C$, Pieterman $H$, van Dijk LC, van Seijen AJ, Derkx FH, Man in't Veld AJ, Schalekamp MA (1999) Inter-observer variability in the angiographic assessment of renal artery stenosis. DRASTIC study group. Dutch Renal Artery Stenosis Intervention Cooperative. J Hypertense 17(12 Pt 1):1731-1736

50. Vasbinder GB, Nelemans PJ, Kessels AG (2001) Diagnostic tests for renal artery stenosis in patients suspected of having renovascular hypertension: a meta-analysis. Ann Intern Med 135:401-411

51. Willoteaux S, Faivre-Pierret $M$, Moranne $O$ (2006) Fibromuscular dysplasia of the main renal arteries: comparison of contrast-enhanced MR angiography with digital subtraction angiography. Radiology 241:922-929

52. Wittenberg G, Kenn W, Tschammler A (1999) Spiral CT angiography. Eur Radiol 9:546-551

53. Zeller T, Frank U, Späth M (2001) Farbduplexsonographische Darstellbarkeit von Nierenarterien und Erkennung hämodynamisch relevanter Nierenarterienstenosen. Ultraschall Med 22:116-121 